\title{
Identification of Early Secretory Antigen Target-6 Epitopes for the Immunodiagnosis of Active Tuberculosis
}

\author{
Donatella Vincenti, ${ }^{1 *}$ Stefania Carrara, ${ }^{*}$ Patrizia De Mori, $^{2}$ Leopoldo P Pucillo, ${ }^{2}$ \\ Nicola Petrosillo, ${ }^{3}$ Fabrizio Palmieri, ${ }^{3}$ Orlando Armignacco, ${ }^{4}$ Giuseppe Ippolito, ${ }^{5}$ \\ Enrico Girardi, ${ }^{5}$ Massimo Amicosante, ${ }^{2}$ AND Delia Goletti ${ }^{1,3}$
}

The early secretory antigenic target (ESAT)-6 purified protein and peptides from Mycobacterium tuberculosis were evaluated as antigens for the immunodiagnosis of tuberculosis (TB). Because the control of TB requires improved diagnostic procedures, efforts have increased to identify Mycobacterium tuberculosis-specific epitopes for the immunodiagnosis of active TB and to discriminate between active and latent states of infection. Two multiepitopic peptides from ESAT-6 protein were selected by computational analysis. Patients with active TB $\left(7 \mathrm{HIV}^{+}\right.$and $\left.20 \mathrm{HIV}^{-}\right)$and control patients $\left(17 \mathrm{HIV}^{+}\right.$and $\left.28 \mathrm{HIV}^{-}\right)$were enrolled. Enzyme-linked immunospot assay analysis for interferon- $\gamma$ expression by peripheral blood mononuclear cells was quantified after stimulation with selected ESAT-6 peptides, purified protein derivative, or the intact ESAT-6 protein. During active TB, 20 of 27 patients responded in vitro to ESAT-6 peptides and 23 of 27 patients to purified protein derivative. None of the controls without active TB, including individuals with latent TB infection, recognized ESAT-6 peptides. By contrast, latently infected individuals did respond in vitro to both intact ESAT-6 protein and purified protein derivative. Thus, high T-cell response frequencies to ESAT-6 peptides are present only during active TB and can be used to discriminate between active and latent forms of infection.

\section{INTRODUCTION}

Tuberculosis (TB) is a global health problem with one-third of the world's population latently infected with Mycobacterium tuberculosis (MTB) and approximately 8 million cases of active disease occurring each year (1). The magnitude of the TB problem has increased in the past decade because of the spread of HIV, which increases the risk of developing active TB (2). In general, infection by MTB is controlled initially by host defenses, and the infection remains latent. However, latent TB infection has the potential to develop into active TB at any time. Because active TB is infectious and leads to the spread of MTB, rapid diagnosis and effective treatment of individuals with active TB are the most important component of TB control programs. Moreover, identification and treatment of persons with latent MTB infection who are at high risk of progressing to active disease, also may contribute to TB control (3). Therefore, an improvement of the methods used to diagnose and discriminate between active and latent TB infection may have a positive effect on TB control, in addition to benefiting individual patients. Currently, microbiological diagnosis of active TB relies on acid fast bacilli (AFB) staining and on culture tests with a sensitivity of $50 \%$ to $70 \%$ and $80 \%$ to $85 \%$, respectively (4). The molecular diagnostic techniques available are reliable for AFB-staining positive samples ( $95 \%$ sensitivity) but not for AFB-staining negative specimens (48\% to 53\% sensitivity) (4,5).
MTB evokes a strong cell-mediated immune response with a high production of interferon (IFN)- $\gamma$, such that the detection of MTB-specific IFN- $\gamma$ T cells may prove a useful diagnostic strategy. Until very recently, the tuberculin skin test has been the only medical tool used to evaluate immune response against MTB in both active and latent TB. However, this test has significant limitations because the purified protein derivative (PPD) used for tuberculin skin test is a crude precipitate of filtered MTB that contains more than 200 antigens widely shared among environmental mycobacteria $(6,7)$. Furthermore, in patients with active $\mathrm{TB}$, the tuberculin skin test is $75 \%$ to $90 \%$ sensitive, but among those with disseminated disease, this sensitivity falls to $50 \%$ (7) and is even lower in $\mathrm{HIV}^{+}$patients with only mild degrees of immunosuppression $(7,8)$. Moreover, a positive tuberculin skin test does not discriminate between latent and active TB. Further clinical workup is needed to obtain a correct diagnosis in subjects with a positive test (4).

In an effort to develop more accurate diagnostic tools, recent studies have led to the identification of the genomic segment RD1, present in MTB but absent from all strains of Mycobacterium bovis bacillus Calmette and Guerin (BCG) as well as almost all environmental mycobacteria $(9,10,11)$. Therefore, RD1 gene products offer the potential for the development of new diagnostic tests that may differentiate MTB infection from BCG vaccination as well as exposure to environmental mycobacteria. Early secretory antigenic target (ESAT)- 6 is a secreted protein encoded by RD1 and has been shown to be a dominant target for cell-medi-

1Translational Research Unit of the National Institute for Infectious Diseases (INMI) "Lazzaro Spallanzani," Rome, Italy; ${ }^{2}$ Laboratory of Clinical Pathology INMI, Rome, Italy; ${ }^{3}$ II Division of Health Department INMI, Rome, Italy; ${ }^{4}$ Division of Infectious Diseases of Belcolle Hospital of Viterbo, Viterbo, Italy; and ${ }^{5}$ Epidemiology Department INMI, Rome, Italy. "D Vincenti and S Carrara contributed equally to this paper. 
Table 1. Demographic and clinical characteristics of participants

\begin{tabular}{|c|c|c|c|c|}
\hline Status & $\mathrm{TB}^{+} \mathrm{HIV}^{+}$ & $\mathrm{TB}^{+} \mathrm{HIV}^{-}$ & $\mathrm{AIDS} / \mathrm{HIV}^{+}$ & $\mathrm{HIV}^{-}$Controls \\
\hline Number of subjects analyzed & 7 & 20 & 17 & 28 \\
\hline Mean age in $y \pm S E$ & $38 \pm 2$ & $32 \pm 3$ & $39 \pm 5$ & $43 \pm 4$ \\
\hline Sex & 6 males, 1 female & 14 males, 6 females & 12 males, 5 females & 21 males, 7 females \\
\hline \multicolumn{5}{|l|}{ Ethnicity } \\
\hline North Africans & 1 & 2 & 2 & 2 \\
\hline Caucasians Western Europe & 5 & 12 & 11 & 21 \\
\hline Caucasians Eastern Europe & - & 2 & 1 & 3 \\
\hline Asian & - & 1 & - & 2 \\
\hline South Americans & 1 & 3 & 3 & - \\
\hline BCG vaccination & 1 & 5 & 7 & 9 \\
\hline \multicolumn{5}{|l|}{ Localization of TB } \\
\hline Pulmonary & 5 & 12 & - & - \\
\hline Extrapulmonary & 1 & 5 & - & - \\
\hline Pulmonary and extrapulmonary & 1 & 3 & - & - \\
\hline HIV-RNA (copies/mL) \pm SE & $46330 \pm 17260$ & - & $33390 \pm 11120$ & - \\
\hline Mean CD4 cell number/ $\mu \mathrm{L} \pm$ SE & $238 \pm 86$ & $713 \pm 94$ & $321 \pm 56$ & $1121 \pm 101$ \\
\hline HAART & 5 & - & 5 & - \\
\hline
\end{tabular}

HAART, highly active antiretroviral therapy.

ated immunity in animal models $(12,13)$, patients with TB $(14,15)$, and household contacts of TB patients who develop TB within $2 \mathrm{y}$ (16). ESAT-6-specific IFN- $\gamma$ secreting CD4 ${ }^{+} \mathrm{T}$ cells were identified as accurate markers of TB infection in both $\mathrm{HIV}^{-}$and $\mathrm{HIV}^{+}$individuals using an ex vivo enzyme-linked immunospot (ELISPOT) assay (17-22). However, in subjects from countries with high rates of exposure to $\mathrm{TB}$, the assay did not allow for the discrimination between latent and active $\mathrm{TB}$, a distinction that is required for better global control of TB $(18,19,23)$.

In this study, we employed a quantitative implemented peptide binding motif analysis (24-27) to identify promiscuous human leukocyte antigen (HLA) class II epitopes encoded in the ESAT-6 protein. We then designed 2 multiepitopic ESAT-6 peptides that were predicted to elicit cellular immune responses in peripheral blood mononuclear cells from individuals with active TB. The diagnostic utility of these peptides was evaluated by analyzing patient samples with IFN- $\gamma$-based ELISPOT and enzymelinked immunosorbent assay (ELISA). Of particular interest was the ability of these peptides to differentially elicit responses between patients with active and latent TB infection.

\section{MATERIALS AND METHODS}

\section{Study Population}

All subjects were prospectively recruited at the National Institute for Infectious Diseases (INMI) "L. Spallanzani" in Rome and at the Division of Infectious Diseases in Belcolle Hospital in Viterbo, Italy. We enrolled 27 patients with clinical and radiographic features consistent with TB and with positive MTB cultures from 1 or more clinical specimens. Among these TB patients, those with pulmonary TB were AFB positive.

As $\mathrm{HIV}^{+}$/AIDS controls, 8 patients without opportunistic infections and 9 AIDS patients with opportunistic infections dif- ferent from TB were enrolled. In particular, the opportunistic infections included neurotoxoplasmosis, intestinal criptosporidiosis, cytomegalovirus retinitis, and recurrent pneumonia $(1,1,2$, and 5 subjects, respectively). As HIV- controls we included 28 individuals with the following pathologies: bacterial pneumonia, pleuritis, bacterial bone infection, tonsillar infection, acute hepatitis B, cirrhosis, bacterial cellulitis, lymphoma, orchitis, and brain abscess $(5,1,1,1,4,3,1,1,1$, and 1 subjects, respectively); 9 individuals were healthy controls.

Information regarding mean age, sex, ethnicity, BCG vaccination, TB localization, HIV-RNA viral load (detected by the Quantiplex HIV-1 RNA version 3.0 assay [bDNA v3.0; Bayer Diagnostics, Emeryville, CA, USA]), CD4 cell counts and number of persons on highly active antiretroviral therapy are shown in Table 1.

After informed consent was obtained, an EDTA blood sample was drawn from enrolled individuals. For TB and AIDS patients, blood samples were obtained within $3 \mathrm{wk}$ of beginning therapy for TB or opportunistic infection. Control subjects underwent tuberculin skin test administered by the Mantoux method using $0.1 \mathrm{~mL}$ (5TU) of Biocinetest-PPD tuberculin (Chiron SpA, Italy) injected intradermally in the volar surface of the forearm. Palpable induration at 48 to $72 \mathrm{~h}$ was measured and recorded. Individuals with an induration $\geq 5 \mathrm{~mm}$ if $\mathrm{HIV}^{+}$or $\geq 10 \mathrm{~mm}^{\text {if } \mathrm{HIV}^{-}}$were classified as positive and underwent chest radiograph and clinical examination to rule out active TB according to the American Thoracic Society Guidelines (4). Latent TB-infected subjects were defined as individuals with a positive tuberculin skin test but without clinical and radiological signs of active TB (4).

\section{Epitope Prediction}

Sequences of the ESAT-6 MTB-specific antigen were obtained by the Swiss-Prot database. The protein sequences then were analyzed by quantitative implemented HLA peptide-binding motifs databases 
Table 2. $\mathrm{CD}^{+}{ }^{+} \mathrm{T}$-cell epitopes in ESAT- 6 protein selected to be broadly recognized in patients with active TB

HLA-class II serological

Position Sequence specificities covered ${ }^{a}$

6-28 WNFAGIEAAASAIQGNVTSIHSL HLA-DR: 1, 3, 4, 8, 11 (5),

$13(6), 52,53$

HLA-DP: 1, 2, 4, 9

HLA-DQ: 1, 2, 5, 6, 8

66-79 NALQNLARTISEA

HLA-DR: $3,8,11(5), 13(6)$, $15(2), 52$

HLA-DP: 4,9

HLA-DQ: 1, 6, 7

aListed are the HLA-class II serological specificities to which the alleles putatively able to bind to the selected peptides belong.

SYFPEITHI (24), EpiPredict (25), and ProPred $(26,27)$ for the identification and scoring of each putative epitope for all the available HLA-class II alleles in the databases. Each selected peptide (Table 2) contained 1 or more epitopes able to bind at least 4 different HLADR, 2 different HLA-DP, and 2 different HLA-DQ specificities with a putative binding ability of $80 \%$ maximum binding for any allele belonging to an HLA-class II serological specificity. Together, the designed peptide epitopes were able to cover more than $90 \%$ of the HLA-class II haplotypes present in different human populations (data not shown). Sequence homology searches of all known protein sequences confirmed that the sequences of the selected peptides were uniquely restricted to MTB complex proteins.

\section{Peptides}

Peptides were synthesized with free amino acid termini using an Applied Biosystem SYNERGY peptide synthesizer and Fmoc chemistry. All synthetic peptides were purified by reverse-phase chromatography to $>90 \%$ purity. Sequence and purity were confirmed by mass spectrometry and analytical reverse-phase chromatography. Lyophilized peptides were diluted in dimethyl sulfoxide (DMSO) at stock concentrations of $10 \mathrm{mg} / \mathrm{mL}$ for each peptide and stored at $-80^{\circ} \mathrm{C}$.

\section{Cell Isolation and Cultures}

Peripheral blood mononuclear cells were separated by standard means and resuspended in a complete medium (RPMI, 10\% heatinactivated fetal calf serum, $10 \mathrm{mM}$ HEPES, $2 \mathrm{mM}$ L-glutamine, and $10 \mathrm{U} / \mathrm{mL}$ penicillin-streptomycin, all from Euroclone Ltd, United Kingdom). Cell cultures with $2 \times 10^{5}$ peripheral blood mononuclear cells were performed in duplicates and seeded in 96-well plates to perform ELISPOT (see Ex Vivo ELISPOT Assay for Single-cell IFN- $\gamma$ Release) or to harvest supernatants to evaluate cytokine production by ELISA (see IFN- $\gamma$ ELISA). In the $\mathrm{HIV}^{+}$patients with $\mathrm{CD}^{+}{ }^{+} \mathrm{T}$-cell counts $<100 / \mu \mathrm{L}, \mathrm{CD}^{+} \mathrm{T}$ cell depletion was performed (see Immunomagnetic Cell Depletions) to enrich the samples in $\mathrm{CD} 4^{+} \mathrm{T}$ cells. In all cases, both cell cultures were treated with the following stimuli: single peptides at 10 and $50 \mu \mathrm{g} / \mathrm{mL}$ or with a pool of the 2 ESAT- 6 peptides at $1 \mu \mathrm{g}$ or $10 \mu \mathrm{g}$ each peptide, PPD (batch RT47; Statens Serum Institut, Copenhagen, Denmark) at $10 \mu \mathrm{g} / \mathrm{mL}$, phytohemagglutinin (PHA) (Sigma, St Louis, MO,
USA) at $5 \mu \mathrm{g} / \mathrm{mL}$, ESAT-6 protein (Lionex, Braunschweig, Germany) at $10 \mu \mathrm{g} / \mathrm{mL}$. Negative controls included peripheral blood mononuclear cells, either unstimulated or treated with DMSO at the same concentration present in the peptide solutions, and peripheral blood mononuclear cells treated with an irrelevant peptide (MHC class II associated invariant chain derived peptide (CLIP), AA 105-117, with the sequence NH2-SKMRMATPLLMQA$\mathrm{COOH}$ ) diluted in complete medium containing the same DMSO concentration used for the ESAT-6 peptides.

\section{Immunomagnetic Cell Depletions}

$\mathrm{CD}^{+} \mathrm{T}$ cell-depleted peripheral blood mononuclear cells were obtained using Dynabeads M-450 (Dynal, Oslo, Norway) and following manufacturer's instructions. These beads reliably deplete 99\% of the target cell population, as evaluated after each experiment by fluorescence activated cell sorter (FACS Calibur) analysis (data not shown).

\section{Ex Vivo ELISPOT Assay for Single-cell IFN- $\gamma$ Release (Enumeration of Circulating Peptide- or Stimulus- specific T Cells from Peripheral Blood)}

Polyvinylidene difluoride-backed plates with 96 wells (MAIPS45; Millipore, Sunnyvale, CA, USA) were precoated with capture antibody (Ab) (IFN- $\gamma$ coating monoclonal, M-700A, Pierce-Endogen Inc, Rockford, IL, USA), dissolved in phosphate-buffered saline at a concentration of $5 \mu \mathrm{g} / \mathrm{mL}$, and kept at $4{ }^{\circ} \mathrm{C}$ overnight. $\mathrm{Ab}$ coated plates were then washed 4 times with $200 \mu \mathrm{L} /$ well sterile PBS. Plates were blocked to prevent nonspecific protein binding with $200 \mu \mathrm{L} /$ well sterile PBS, containing 10\% fetal calf serum for $2 \mathrm{~h}$ at room temperature. Peripheral blood mononuclear cells stimulated as described above were incubated for $40 \mathrm{~h}$ at $37^{\circ} \mathrm{C}$ in $5 \% \mathrm{CO}_{2}$. Cells then were removed by 4 rinses with $200 \mu \mathrm{L} /$ well of PBS followed by 4 additional rinses with $200 \mu \mathrm{L} /$ well of PBS/ $0.05 \%$ Tween ${ }^{\circledR} 20$ (Sigma). Incubation for $100 \mathrm{~min}$ with secondary anti-IFN- $\gamma$ biotin-labeled Ab (Ab M-701B, Pierce-Endogen) diluted in PBS/4\% bovine serum albumin (fraction V, Sigma) at a concentration of $1 \mu \mathrm{g} / \mathrm{mL}$, was followed by streptavidin-HRP (Pierce-Endogen) for $30 \mathrm{~min}$ at room temperature in the dark. AEC substrate (AEC staining kit, AEC101, Sigma) was added, and plates were observed for spot development for up to $20 \mathrm{~min}$ at room temperature in the dark. Plates were then washed with distilled water to stop the reaction and allowed to dry overnight. Spots then were counted by an automated ELISA-spot assay video analysis system (A-EL-VIS, Hannover, Germany). Evaluated spots had a size $>15 \mathrm{U}\left(1 \mathrm{U}=500 \mu \mathrm{m}^{2}\right)$.

When the average number of spot-forming cells in duplicate wells of stimulated cultures (with PPD, PHA, ESAT-6 protein, or ESAT-6 peptides) exceeded that in controls by 5 spot-forming cells and were at least 2-fold higher, the responses were scored as positive (17-22). To obtain the absolute value, the number of spotforming cells in the negative controls was subtracted from the number of spot-forming cells in the stimulated cultures. In particular, negative controls for the ESAT-6 peptide-stimulated peripheral blood mononuclear cells included the average number of spots obtained in peripheral blood mononuclear cells treated with the same DMSO concentration used to dilute the peptides and the 
average number of spots obtained in peripheral blood mononuclear cells treated with CLIP. As negative controls for blood mononuclear cells stimulated with PPD, PHA, or ESAT-6 protein, the average number of spots produced by unstimulated peripheral blood mononuclear cells was used.

\section{IFN- $\boldsymbol{\gamma}$ ELISA}

Half of the volume of the supernatants, removed on day 7 from the cell cultures seeded in 96-well round-bottom plates (Costar, Corning Inc, NY, USA), was stored at $-80^{\circ} \mathrm{C}$ to evaluate cytokine production. An IFN- $\gamma$ commercial kit was employed according to the manufacturer (R\&D Systems, Minneapolis, MN, USA). Results were expressed as $\mathrm{pg} / \mathrm{mL}$ per million peripheral blood mononuclear cells. Responses in stimulated peripheral blood mononuclear cells (with PPD, PHA, ESAT-6 protein, or ESAT-6 peptides) were scored as positive if the IFN- $\gamma$ production in test wells was 3-fold higher than in negative controls (15). To obtain the absolute value, the number of IFN- $\gamma$ production in negative controls was subtracted from the value obtained in the stimulated cultures. Negative controls for the ESAT-6 peptide-peripheral blood mononuclear cells included peripheral blood mononuclear cells treated with the same DMSO concentration used to dilute the peptides and peripheral blood mononuclear cells treated with CLIP. Unstimulated peripheral blood mononuclear cells were used as negative controls for peripheral blood mononuclear cells stimulated with PPD, PHA, or ESAT-6 protein.

\section{Statistical Analysis}

Differences between groups were evaluated by the Mann-Whitney $U$ test, by Fisher test, and Pearson r. $P$ values $\leq 0.05$ were considered significant. To define a positive criterion that would maximize the discrimination ability of the assay and minimize the number of erroneous diagnoses of active TB, a receiver operator characteristic curve was constructed for ELISA and ELISPOT data using LABROC-1 software.

\section{RESULTS}

\section{Selection of MTB Promiscuous Epitopes}

To overcome the restriction imposed by the patients' HLAhaplotypes in the analysis of MTB-specific T-helper response, we selected 2 areas of ESAT- 6 by quantitative implemented peptide binding motif analysis. These areas contained promiscuous epitopes (ESAT-6 $6-28$ and ESAT-6 66-79) (see Table 2) that were able to bind more than $90 \%$ of the HLA-class II haplotypes present in different human populations (28). ESAT-6 induces a strong cellmediated immune response (29) and is actively secreted by dividing mycobacteria $(30,31)$. Both ESAT-6-derived peptides were multiepitopic as they contained differently recognized T-cell epitopes relevant to natural processing pathways (17).

\section{ESAT-6 Peptide-specific IFN- $\gamma$-secreting T Cells in TB Patients With or Without HIV Infection at the Time of TB Diagnosis}

At the time of TB diagnosis, the number of ESAT- 6 peptidespecific IFN- $\gamma$-secreting $\mathrm{T}$ cells in TB patients with or without
HIV infection was determined. All of the TB patients included in the study had positive MTB cultures, and all of the pulmonary TB patients were AFB positive. To score the results as positive, either the response ratio of stimulated compared with unstimulated peripheral blood mononuclear cells was calculated or in the case of ESAT-6 peptides, a receiver operator characteristic curve was constructed to calculate a cutoff value of 32 spot-forming cells and $76 \mathrm{pg} / \mathrm{mL}$ IFN- $\gamma$ per million peripheral blood mononuclear cells for ELISPOT and ELISA, respectively. Both approaches yielded identical results in terms of scoring the samples as positive or negative.

A comparison between the data obtained by the ELISPOT and ELISA assays was performed in 13 individuals with active TB (Table 3). The ELISPOT assay was shown to be more sensitive compared with ELISA in 4 of 13 TB patients studied (see Table 3, patient code: $1,3,9,10$ ), as previously indicated with different experimental approaches in the literature $(32,33)$. Given the higher sensitivity of the ELISPOT, further analyses were restricted to this assay system.

As shown in Figure 1, a significant difference in the number of IFN- $\gamma$ spot-forming cells was observed between the $\mathrm{TB}^{+} \mathrm{HIV}^{+}$ group and the control $\mathrm{HIV}^{+}$group $(P=0.0001)$, and between the $\mathrm{TB}^{+} \mathrm{HIV}^{-}$and the control $\mathrm{HIV}^{-}$groups $(P=0.0001)$. No statistical correlation was observed between the response magnitude to ESAT-6 peptide pool and either $\mathrm{CD}^{+}{ }^{+}$T-cell count (Pearson $\mathrm{r}=0.4$, $P>0.05$ ) or plasma HIV-viremia (Pearson $r=0.25, P>0.05$ ).

A summary of the data obtained from in vitro responses to individual ESAT-6 peptides, pooled peptides, and PPD is shown in Table 4. Of note, among all patients with active TB, either $\mathrm{HIV}^{+}$ or $\mathrm{HIV}^{-}$, a positive response to the pool was observed in 20 of 27 $(P<0.0001)$ compared with 0 of 45 controls, whereas a positive response to PPD was found in 23 of $27(P<0.01)$ compared with 26 of 45 controls. Thus, among controls without active TB, regardless of HIV status, none were scored positive to the pooled peptides although $58 \%$ responded in vitro to PPD. The sensitivity of the assay among the whole population studied was 74\% (20 of 27) and the specificity was $100 \%$.

\section{Association of the In Vitro Response to ESAT-6 Peptides with Active TB}

It has been reported previously that subjects with latent TB infection may respond to ESAT-6 peptides and to the whole ESAT-6 protein (17-21). To evaluate whether peptides selected by computational analysis would allow for the reliable discrimination between active and latent TB, peripheral blood mononuclear cells from 12 patients with active TB that responded in vitro to the ESAT-6 peptide pool, and 19 subjects with latent TB infection (defined by a positive tuberculin skin test with no clinical or radiological signs of active TB) were tested (4).

As shown in Figure 2, of the patients with active TB, 92\% (11 of 12) recognized the ESAT- $6_{6-28}$ peptide, $33 \%$ (4 of 12) recognized the ESAT-6 $66-79$ peptide, and all recognized either the whole ESAT-6 protein or PPD (12 of 12). By contrast, no response to ESAT-6 peptides, either pooled or separate, was observed in peripheral blood mononuclear cells from individuals with latent TB infection, whereas a response to the whole ESAT-6 protein or PPD 
Table 3. In vitro ESAT-6 peptides pool response in terms of IFN- $\gamma$ production evaluated simultaneously by ELISA and ELISPOT assays in HIV ${ }^{+}$ and HIV- individuals with active TB

\begin{tabular}{|c|c|c|c|c|c|}
\hline $\begin{array}{l}\text { Patients } \\
\text { Code }\end{array}$ & HIV Status & $\begin{array}{c}\text { ELISA }^{a}(\mathrm{pg} / \mathrm{mL} \\
\text { per million PBMC) }\end{array}$ & ELISA $^{a}$ (score) & $\begin{array}{l}\text { ELISPOTb (SFCS } \\
\text { per million PBMC) }\end{array}$ & ELISPOT ${ }^{\mathrm{b}}$ (score) \\
\hline 1 & + & 70 & - & 55 & + \\
\hline 2 & + & 215 & + & 265 & + \\
\hline 3 & + & 63 & - & 100 & + \\
\hline 4 & + & 0 & - & 30 & - \\
\hline 5 & - & 215 & + & 145 & + \\
\hline 6 & - & 750 & + & 60 & + \\
\hline 7 & - & 163 & + & 215 & + \\
\hline 8 & - & 1450 & + & 110 & + \\
\hline 9 & - & 63 & - & 55 & + \\
\hline 10 & - & 0 & - & 85 & + \\
\hline 11 & - & 0 & - & 15 & - \\
\hline 12 & - & 3275 & + & 155 & + \\
\hline 13 & - & 0 & - & 10 & - \\
\hline
\end{tabular}

aFor the ELISA, the positive response cutoff was $76 \mathrm{pg} / \mathrm{mL}$ per million PBMC above negative controls (see Materials and Methods).

${ }^{b}$ For the ELISPOT assay, the positive response cutoff was 32 spot-forming cells per million PBMC above negative controls (see Materials and Methods).

PBMC, peripheral blood mononuclear cells; SFC, spot-forming cells.

was present in $73 \%$ (14 of 19) and 100\% (19 of 19) of the individuals studied, respectively. Thus, ESAT- 6 selected peptides, rather than the intact ESAT-6 protein or PPD, allow for the rapid detection of active TB, and discriminate between active and latent disease.

\section{DISCUSSION}

In this pilot study, we established an immune assay for the diagnosis of active in contrast to latent TB. To this end, we designed 2 multiepitopic peptides based on ESAT-6, a protein highly specific to MTB, that triggers IFN- $\gamma$ production in peripheral blood mononuclear cells in an antigen-specific manner. We found that responses to these ESAT-6 peptides, as measured by ELISPOT, were strongly associated with active TB. In contrast, peripheral blood mononuclear cells from patients with latent TB infection failed to respond to either of the 2 ESAT- 6 peptides, although they responded to the whole ESAT-6 protein. Of note, we were able to detect these ESAT-6 peptide specific responses in both $\mathrm{HIV}^{+}$and $\mathrm{HIV}^{-}$patients with active TB. The overall sensitivity of our immune diagnostic assay in patients with active TB, based on data obtained by ELISPOT assay, was $74 \%$ with a specificity of $100 \%$.

ESAT-6 was chosen because it is a dominant target for cellmediated immunity in animal models $(12,13)$ and in patients with TB $(14,15,17)$. Further, ESAT-6 peptide-specific IFN- $\gamma$-secreting $\mathrm{CD}^{+} \mathrm{T}$ cells have been recently identified as accurate markers of MTB infection in patients with culture-confirmed active disease (18). In our study, ESAT-6 selected peptides were identified by using quantitative implemented peptide-binding motif analysis to define epitopes that cover all the patients' HLA haplotype. Our results demonstrate the utility of the selected ESAT- ${ }_{6-28}$ peptide as a tool for the diagnosis of active TB in both $\mathrm{HIV}^{+}$and $\mathrm{HIV}^{-}$ patients. Of note, this peptide is highly recognized by a genetically heterogeneous population, and despite the limitation inherent in the use of a small population, we found that $92 \%$ of the subjects that responded to the pooled peptides mounted a positive response to the ESAT- $6_{6-28}$ peptide alone. This response rate is substantially greater than that previously reported for a single ESAT-6 peptide, ESAT- $6_{1-15}$, for which the maximum response rate was $57 \%$ (18). The higher frequency of the response obtained using ESAT- $6_{6-28}$ is probably related to the potential of this multiepitopic peptide (see Table 2) to enter into an increased number of natural processing pathways (16), thus allowing a better presentation in the context of MHC class II alleles and T-cell recognition. In this context, it seems likely that the responses obtained with our

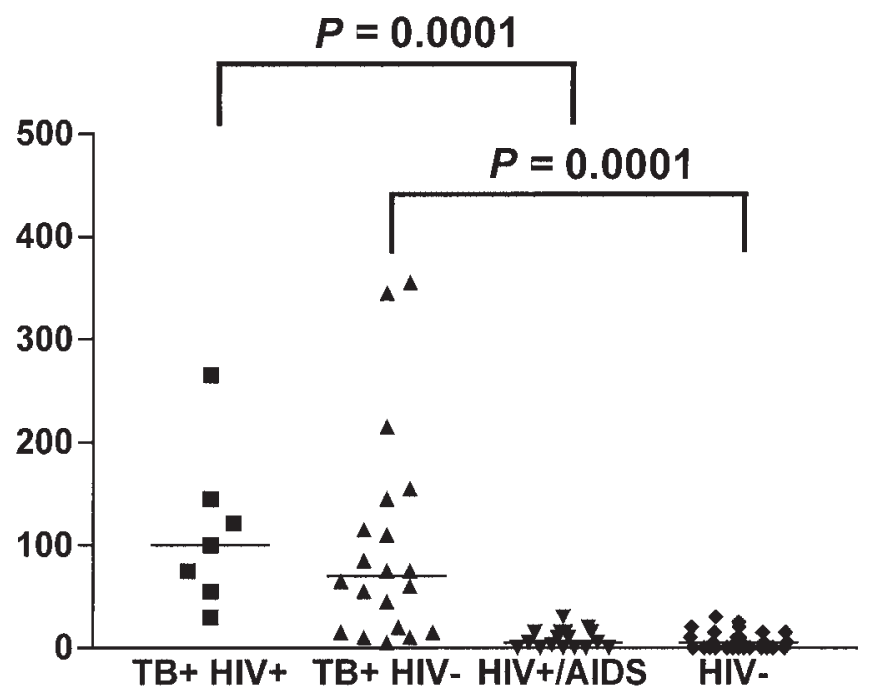

Figure 1. IFN- $\gamma$ response to ESAT-6 peptides in patients with active TB and controls. Detection of IFN- $\gamma$ was performed by ELISPOT assay in $\mathrm{HIV}^{-}$and $\mathrm{HIV}^{+}$patients with or without active TB. The highest number of ESAT-6peptide specific IFN- $\gamma$-secreting T cells (spot-forming cells) is reported for each individual. Horizontal bars represent the mean of the spot-forming cells for each group of patients. The $P$ values denote the difference between the responders in each group of patients. 
Table 4. In vitro ESAT-6 peptide pool and PPD responses in terms of IFN- $\gamma$ production evaluated by ELISPOT assay in $\mathrm{HIV}^{+}$and $\mathrm{HIV}^{-}$individuals with or without active TB disease

\begin{tabular}{lcccccc} 
& \multicolumn{2}{c}{ In vitro } & & \\
& ESAT-6 peptide & & \multicolumn{2}{c}{$\begin{array}{l}\text { In vitro PPD } \\
\text { pool responses }\end{array}$} & & \multicolumn{2}{c}{ responses } \\
\cline { 2 - 3 } \cline { 6 - 7 } & TB & No TB & & TB & No TB \\
\hline Positive responses/total cases & $20 / 27^{a}$ & $0 / 45$ & & $23 / 27^{b}$ & $26 / 45$ \\
Percentage & 74 & 0 & & 85 & 58 \\
\hline
\end{tabular}

ap $<0.0001$ compared with no TB cases.

bP $<0.01$ compared with no TB cases.

ESAT- $6_{6-28}$ peptide is the sum of the responses obtained with single peptides of ESAT-6 (ESAT- $6_{1-15}$, ESAT-6 $6-20$, ESAT- $6_{11-25}$, and ESAT- $\left.6_{16-30}\right)$ that have previously been evaluated $(17,18,20,21)$. The response to the pool of ESAT- 6 peptides was shown to be useful because all TB patients responding in vitro to single peptides also responded to the peptides pool.

The in vitro ESAT-6 peptide-based immunological assay described in this study presents a sensitivity of $74 \%$ and suggests that the absence of a response in some patients with active TB may be due to their particular state of immune suppression. In particular, 1 of the nonresponder patients was under corticosteroid therapy and 6 subjects had severe multiorgan TB. The lack of a response in these patients is in agreement with previously published observations reporting the absence of a response to ESAT-6 in peripheral blood mononuclear cells from patients with radiographically determined severe TB disease (15). The sensitivity for TB diagnosis reported in the literature using unselected ESAT- 6 peptides is higher compared with what we described $(16,18,19)$; however, in those studies it was not possible to discriminate between active and latent TB. In our study, in persons with latent TB infection characterized by a positive tuberculin skin test, we demonstrated an in vitro response to PPD (19 of 19) and to the whole ESAT-6 protein (14 of 19), but not to the related selected peptides (0 of 19). These data demonstrate a strong association between the ESAT-6peptides elicited responses and active TB. This suggests that T-cells with specificity to these peptides are present at high frequency during active disease but not during latent infection. In addition, note that in our study, 13 of 45 control subjects had recently immigrated (less than 2 y) from countries with a high burden of TB (see Table 1); however none of them responded to the ESAT-6 peptides despite the fact that they had positive tuberculin skin tests. If confirmed with a larger number of patients, these results indicate that ESAT-6 peptides could be used to reliably distinguish between active and latent infection.

Regarding the patients with latent TB infection, we note that the in vitro positive response to ESAT-6 protein could be related to infection with mycobacteria different from MTB, such as Mycobacterium kansasii, szulgai, flavescens, and marinum because the ESAT-6 gene also is present in these atypical mycobacteria (34). Moreover an ESAT-6 homologue has recently been identified in Mycobacterium leprae and some MTB-infected individuals showed cross-reactivity with this antigen (35). Although none of the individuals in this study presented clinical signs or a previous history of leprosy or of a disease associated with the mycobacteria mentioned above, we cannot rule out the possibility that individuals were exposed to them. In addition, to confirm the specificity of our assay, it will be important to include in future studies patients with mycobacterial diseases other than TB.

Diagnosis of $\mathrm{TB}$ in $\mathrm{HIV}^{+}$patients is difficult $(36,37)$, and this is a significant global problem. HIV disease occurs throughout the world especially in countries with limited resources (1). Thus, it is important to have reliable diagnostic tests that identify active TB in $\mathrm{HIV}^{+}$patients. Within the $\mathrm{HIV}^{+}$group studied here, the sensitivity of the assay was $86 \%$ (6 of 7) and was comparable with the sensitivity reported in the $\mathrm{HIV}^{-}$group $(70 \%, 14$ of 20$)$. Surprisingly, the magnitude of the response to ESAT-6 peptide pool did not correlate with either $\mathrm{CD}^{+}{ }^{+} \mathrm{T}$-cell counts or with plasma HIV-RNA levels. Certainly, further studies on a larger number of patients are necessary to better define the relationship between plasma viremia, $\mathrm{CD}^{+}{ }^{+} \mathrm{T}$-cell counts, and responsiveness to our ESAT-6 peptides. A recent paper by Chapman and others (19) describes the detection of $\mathrm{TB}$ infection in $\mathrm{HIV}^{+}$individuals using the ELISPOT assay for IFN- $\gamma$ performed with unselected peptides from ESAT-6 and culture filtrate protein-10. Whereas this report is important because it clearly demonstrates the utility of such an assay in diagnosing $\mathrm{TB}$ in immunocompromised patients, the assay employed in their study cannot discriminate between active and latent TB.

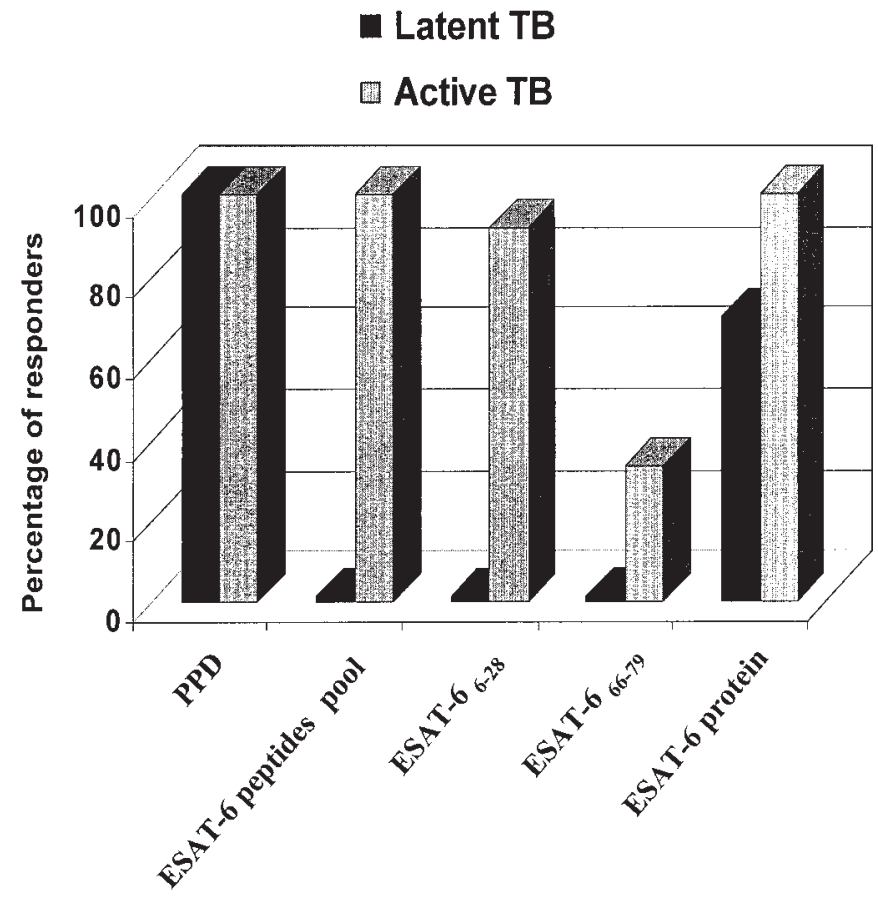

Figure 2. Association of the in vitro response to ESAT-6 peptides to active TB. The in vitro response to PPD, to the pool of ESAT-6 peptides, and to the whole ESAT-6 protein are shown in patients with active TB compared with those with latent TB infection. Mapping was defined by peptidespecific IFN- $\gamma$ ELISPOT assay responses for 12 of the patients with active TB responsive to ESAT-6 peptide pool. The figure shows the percentage of subjects responding to the pool of ESAT-6 peptides and, among these, the percentage of responders to each single peptide. 
In conclusion, we have demonstrated that multiepitopic peptides derived from ESAT-6 using computational analysis can be used to diagnose active TB and, more importantly, to discriminate between active TB and latent TB. By employing the ELISPOT method to detect IFN- $\gamma$-producing cells, an accurate diagnosis of active TB can be obtained in $2 \mathrm{~d}$ compared with the 15 to $40 \mathrm{~d}$ required for a diagnosis that relies on bacterial cultures $(5,6)$, thus allowing prompt and correct therapy. While we could not evaluate the predictive value of the assay because of the method used for patient enrollment (that is, patients were deliberately chosen with active TB without performing a prospective enrollment of individuals with suspected TB), the negative and positive predictive values of our immunological assay, if applied to a population of patients with suspected TB in an industrial country with a prevalence of active diseases of $6 \%$ (38), would be $98.4 \%$ and $100 \%$, respectively. Within a population with a higher prevalence of TB, that is, $40 \%$, the negative predictive value would drop to $85.2 \%$. Although the sensitivity of this assay requires further improvement, its capacity to aid in the identification of active infections may prove useful in suppressing the transmission of TB.

\section{ACKNOWLEDGMENTS}

The authors are grateful to all patients and the nursing staff who took part in this study. We thank $V$ Colizzi and F Poccia for the helpful discussions, M Brescia for technical assistance, R Urso, M De Marco, R MaddaIuno, and A Govoni for helping in the recruitment of patients, Jim Arthos, Zana Mariano, and Carla Nisii for editing the manuscript, and Massimo Carrara for helping with the graphics. This work was supported by Current Research Project of the Italian Ministry of Health grants.

Address correspondence and reprint requests to Delia Goletti, Laboratorio di collegamento tra ricerca di base e clinica, "Padiglione Del Vecchio," Istituto Nazionale per le Malattie Infettive "Lazzaro Spallanzani," IRCCS, Roma 00149, Italia. Phone: +39-655170-954 (961); fax: +39-6-55170-904; e-mail: d.goletti@tiscali.it.

Submitted October 29, 2002; accepted for publication February 12, 2003.

\section{REFERENCES}

1. Dye C, Scheele S, Dolin P, Pathania V, Raviglione MC. (1999) Consensus statement. Global burden of tuberculosis: estimated incidence, prevalence, and mortality by country. WHO global surveillance and monitoring project. JAMA 282:677-86.

2. Di Perri G et al. (1989) Nosocomial epidemic of active tuberculosis among HIVinfected patients. Lancet 2:1502-4.

3. Jasmer RM, Nahid P, Hopewell PC. (2002) Latent tuberculosis infection. New Eng. J. Med. 347:1860-6.

4. American Thoracic Society. (2000) Diagnostic standards and classification of tuberculosis in adults and children. Am. J. Respir. Crit. Care Med. 161:1376-95.

5. Forbes BA. (1997) Critical assessment of gene amplification approaches on the diagnosis of tuberculosis. Immunol. Invest. 26:105-16.

6. Fine PE et al. (1999) Tuberculin sensitivity: conversions and reversions in a rural African population. Int. J. Tuberc. Lung Dis. 3:962-75.

7. Huebner RE, Schein MF, Bass JB Jr. (1993) The tuberculin skin test. Clin. Infect. Dis. 17:968-75.

8. Shafer RW, Edlin BR. (1996) Tuberculosis in patients infected with human immunodeficiency virus: perspective on the past decade. Clin. Infect. Dis. 22:683-704.

9. Behr MA et al. (1999) Comparative genomics of BCG vaccines by wholegenome DNA microarray. Science 284:1520-3
10. Arend SM et al. (2002) Tuberculin skin testing and in vitro T cell responses to ESAT-6 and culture filtrate protein 10 after infection with Mycobacterium marinum or M. kansasii. J. Infect. Dis. 186:1797-807.

11. Mahairas GG, Sabo PJ, Hickey MJ, Singh DC, Stover CK. (1996) Molecular analysis of genetic differences between Mycobacterium bovis BCG and virulent $M$. bovis. J. Bacteriol. 178:1274-82.

12. Andersen $P$, Andersen AB, Sorensen AL, Nagai S. (1995) Recall of long-lived immunity to Mycobacterium tuberculosis infection in mice. J Immunol 154:335972

13. Pollock JM, Andersen P. (1997) Predominant recognition of the ESAT-6 protein in the first phase of interferon with Mycobacterium bovis in cattle. Infect. Immun. 65:2587-92.

14. Ulrichs T et al. (1998) Differential T cell responses to Mycobacterium tuberculosis ESAT6 in tuberculosis patients and healthy donors. Eur. J. Immunol. 28:3949-58.

15. Ravn P et al. (1999) Human T cell responses to the ESAT-6 antigen from Mycobacterium tuberculosis. J. Infect. Dis. 179:637-45.

16. Doherty TM et al. (2002) Immune responses to the Mycobacterium tuberculosisspecific antigen ESAT-6 signal subclinical infection among contacts of tuberculosis patients. J. Clin. Microbiol. 40:704-6.

17. Lalvani A et al. (2001) Enhanced contact tracing and spatial tracking of Mycobacterium tuberculosis infection by enumeration of antigen-specific T cells. Lancet 357:2017-21.

18. Lalvani A et al. (2001) Enumeration of T cells specific for RDl-encoded antigens suggests a high prevalence of latent Mycobacterium tuberculosis infection in healthy urban Indians. J. Infect. Dis. 183:469-77.

19. Chapman AL et al. (2002) Rapid detection of active and latent tuberculosis infection in HIV-positive individuals by enumeration of Mycobacterium tuberculosis-specific T cells. AIDS 16:2285-93.

20. Lalvani A et al. (2001) Rapid detection of Mycobacterium tuberculosis infection by enumeration of antigen-specific T cells. Am. J. Respir. Crit. Care Med. 163:824-8

21. Pathan AA et al. (2001) Direct ex vivo analysis of antigen-specific IFN- $\gamma$-secreting CD4 T cells in Mycobacterium tuberculosis-infected individuals: association with clinical disease state and effect of treatment. J. Immunol. 167:5217-25.

22. Elhay MJ, Oettinger T, Andersen P. (1998) Delayed-type hypersensitivity responses to ESAT-6 and MPT64 from Mycobacterium tuberculosis in the guinea pig. Infect. Immun. 66:3454-6.

23. Cardoso FL et al. (2002) T-cell responses to the Mycobacterium tuberculosisspecific antigen ESAT-6 in Brazilian tuberculosis patients. Infect. Immun. 70:670714.

24. Rammensee H, Bachmann J, Emmerich NP, Bachor OA, Stevanovic S. (1999) SYFPEITHI: database for MHC ligands and peptide motifs. Immunogenetics 50:213-9. Refer to http://www.syfpeithi.de

25. Fleckenstein B, Jung G, Wiesmüller KH. (1999) Quantitative analysis of peptideMHC class II interaction. Semin. Immunol. 11:405-16. Refer to http:// www.epipredict.de

26. Sturniolo T et al. (1999) Generation of tissue-specific and promiscuous HLA ligand database using DNA microarrays and virtual HLA class II matrices. Nat. Biotechnol. 17:555-61. Refer to http://www.imtech.res.in/raghava/propred/page2.html

27. Singh H, Raghava GP. (2001) ProPred: prediction of HLA-DR binding sites. Bioinformatics 17:1236-7.

28. Proceedings of the 12th IHWC. (1997) HLA genetic diversity of HLA functiona and medical implication. Charron D. (ed) EDK Medical and Scientific International Publisher, Paris.

29. Andersen AB, Brennan P. (1994) Proteins and antigens of Mycobacterium tuberculosis. In: Tuberculosis. Bloom B. (eds.) ASM Press, Washington DC. pp. 307-32.

30. Orme IM. (1988) Induction of nonspecific acquired resistance and delayedtype hypersensitivity, but not specific acquired resistance in mice inoculated with killed mycobacterial vaccines. Infect. Immun. 56:3310-2.

31. Andersen P, Heron I. (1993) Specificity of protective memory immune response against Mycobaterium tuberculosis. Infect. Immun. 61:844-51.

32. Tanguay S, Killion JJ. (1994) Direct comparison of ELISPOT and ELISA-based assays for detection of individual cytokine-secreting cells. Lymphokine Cytokine Res. 13:259-63.

33. Favre N, Bordmann G, Rudin W. (1997) Comparison of cytokine measurements using ELISA, ELISPOT and semi-quantitative RT-PCR. J. Immunol. Methods 204:57-66.

34. Harboe M, Oettinger T, Wiker HG, Rosenkrands I, Andersen P. Evidence for occurrence of the ESAT-6 protein in Mycobacterium tuberculosis and virulent Mycobacterium bovis and for its absence in Mycobacterium bovis BCG. Infect. Immun. 1996; 64:16-22.

35. Geluk A et al. (2002) Identification and characterization of the ESAT-6 homologue of Mycobacterium leprae and T-cell cross-reactivity with Mycobacterium tuberculosis. Infect. Immun. 70:2544-8.

36. Shafer RW, Kim DS, Weiss JP, Quale JM. (1991) Extrapulmonary tuberculosis in patients with human immunodeficiency virus infection. Medicine 70:384-97.

37. Chaisson RE et al. (1987) Tuberculosis in patients with the acquired immunodeficiency syndrome. Clinical features, response to therapy and survival. Am. Rev. Respir. Dis. 136:570-4

38. Divinagracia RM, Timothy JH, Stanley B, Schluger NW. (1998) Screening by specialists to reduce unnecessary test ordering in patients evaluated for tuberculosis. Chest 114:681-4. 